\title{
SIMULATION SYSTEM OPTIMIZE THE TIME OF PROCESS
}

\author{
Dyah Lintang Trenggonowati ${ }^{* 1)}$ \\ 1) Industrial Engineering Department, Engineering Faculty, Sultan Ageng Tirtayasa University \\ Jl. Jend. Sudirman KM.3 Cilegon 42435, Indonesia
}

\begin{abstract}
PT. LTX is a company engaged in manufacturing that produce tin plate coil form. Coil packaging process needs to be done before it is sent to the customer. In the process of packaging the coil is found on the machine appender bottleneck causing measurement stations of diameter and wrapping coil to be delayed which makes the time coil packaging is not optimal. This study aims to determine the simulation model of the existing coil packaging process, determining the proposed improvements to optimize the timing of coil packaging process, as well as find out the time optimal coil packaging process. This study uses a software simulation with ProModel 7.5. ProModel simulation results showed that the average time coil packaging process for 657.81 hours per month, so that made three design alternatives and the best improvement is the third alternative with the addition of resources such as forklifts and additional mounting stations crown that yield an average of 315.296 hours per month.
\end{abstract}

Keywords: ProModel Software; Simulation; Time Optimization

\section{Introduction}

Along with the development of enterprises in manufacturing in the world is rapidly increasing, companies with a high production capacity, and requires a strategy and good planning to optimize production time. A production system is complex and has many processes if it is not controlled continuously can lead to large losses as a result of the production process errors. PT. LTX is a company engaged in manufacturing that produce tin plate coil form. In the process of making its products, some of the processes involve with the processes of machine and human that have uncertainty at the time of workmanship. This study focuses on the packaging of the product coil.

The process of packaging the coil consists of a packaging station with the working elements of diameter measurement and wrapping coil average over 238 seconds, the manufacture of pallets on average for 91 seconds, and the installation of pallet and the installation of crown in appender machine on average over 314 seconds. Process the installation of pallet and mounting crown in appender machine has the longest processing time so the process is a bottleneck in the process of packaging the coil and cause the packaging station into delay, then it can make a production process is not optimal. Based on data from the company, PT. LTX average wrap 1345 coil with a time of 669 hours per month, the time used to wrap for the one coil is 30 minutes. By minimizing delay and bottleneck, PT. LTX can accelerate the process of packaging the coil, then the process time of packaging coil will be more optimized and can obviate the waste of time, so as to produce and deliver the final product on time to improve profits and the competitive position of company are achieved through the efforts of maintaining customer loyalty. In addition, the company can also save costs with the use of working hours more effectively and efficiently.

Under these conditions, from the researchers want to solve these problems to optimize the production process time by using software Promodel 7.5. In this study aims to determine the process simulation model of the existing coil packaging, determining the proposed improvements to optimize the timing of coil packaging process, as well as find out the time optimal coil packaging process.

\section{Research Method}

The research methodology explains the steps undertaken from baseline to get the desired results. This research was conducted at PT. LTX. PT. LTX is a company engaged in manufacturing that produce tin plate coil form. In the process of making its products, some of the processes involved with the machine and human processes that have uncertainty at the time pengerjaanya. This study focuses on the packaging of the product coil. The method used in this empirically is a computer simulation model with the software Pro Model 7.5. This study begins with the problems in the process of packaging the coil is found on the bottleneck of 
appender machine causing measurement stations and wrapping coil diameter into delayed which makes the time coil packaging is not optimal. To solve these problems, researchers took some time data from each machine packaging process appender to be processed by using test statistic such as correlation, scatter plots, run test, parameter estimation and goodness of fit. After that, the model verification and validation to make initial simulation model (conceptual). The proposed model is based on the output of ProModel simulation. Furthermore, the proposed model were compared with the initial model (existing) to obtain better result. The proposed model can be applied by the company. However, it all depends on the company's proposed model would be taken.

\section{Conceptual Model}

3.1. Problem Element

The problem is the dissatisfaction of individual or group of individuals on the current conditions (current state of affairs). Individu or group of people that know the targets were not met, but also have control (control) to the problems that exist. So if the control is used, the goal can be achieved. In achieving these objectives, needed a troubleshooting by identifying Problem Element (Daellenbach, 1994). Here is the Problem Element in research on optimization and simulation time the product packaging process coil in PT. LTX.

\section{Decision Maker}

Decision Maker or decision makers are individuals or groups of people who have the authority to control the problem. Problem is also called the Owner or in other words, the unsatisfactory situation (problem) is viewed by who is. Decision Maker in the process of packaging the product coil in PT. LTX is Head of Production Division.

2. The Objective

The Objective is the purpose of the study so that the target can be achieved .The Objective or purpose does research on optimization and simulation time packaging process in PT. LTX is to optimize the packaging process time of coil product.

3. Performance Measure

Performance Measure is a measure of performance to determine whether the purpose of the study has been reached. Performance Measure in research at PT. LTX is the number of coil units which are undergoing a process of packaging.

4. Alternatif Courses of Action

Alternative Courses of Action is an action alternatives will be selected to achieve the purpose of study or decision variables. In research on optimization and simulation time the product packaging process coil in PT. LTX, a proposed alternative measures of problem solving is to minimize the delay and WIP.

\subsection{Element System}

Element System is a component in the system that defines what, when, and how the occurrence of a process in the system. In building a model of the desired system, ProModel software provides several elements that have been adapted to create a model of the production system. Here is an Element System in research on optimization and simulation time the product packaging process coil in PT. LTX:

\section{Location}

Location is somewhere in the system that does not move in which the entity will undergo the process, as a storage place or places for activities. Location in the process of packaging the product coil in PT. LTX include Warehouse, Process Measurement and Coil Packaging (Packaging), Pallet Manufacturing Process, Apender and Storage.

2. Entity

Entity is something which is the object of a process. Entity in the simulation model in research at PT. LTX is a product coil, pallet and timber.

3. Arrival

Arrivals declare the arrival of entity from outside into the system. Arrivals in research at PT. LTX include the arrival of coil products from warehouse to the packing station and the measurement coil and the arrival of a buffer beam in pallet to pallet manufacture.

4. Resources 
Resources are resources, human or a piece of equipment and other supplies were tasked to escort or move an entity. Resources which are in the packaging PT. LTX include the use of a forklift in the process of moving the coil from the warehouse to the measuring station and packing, transporting pallet from the station towards Appender pallet manufacture, transfer coil of the measuring stations and wrapping to Appender, as well as transporting coil which has undergone a process of packaging heading Storage. But in Apender stations using the conveyor to install crown.

\section{Result And Discussion}

In this research, data processing using data obtained After getting the data to design a simulation model eksiting using ProModel software 7.5 (Charles, 2003). Here is the layout of the existing models:

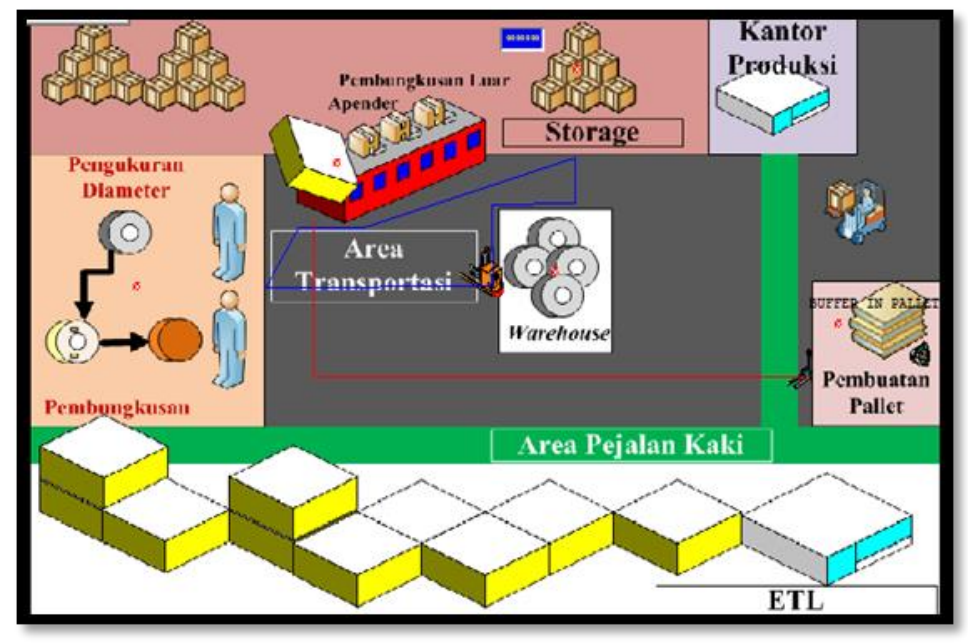

Figure 4.1 Existing Model PT. LTX

Once the existing simulation models are created, replication test, test verification and test validation.

\subsection{Test Replication}

Determination of Total Replication Model. From the simulation results with the initial replication $(\mathrm{n} 0=$ 10) were obtained the following data:

Table 4.1 Results the Calculation Recapitulation of Existing Simulation Models

\begin{tabular}{|c|c|c|c|c|c|c|c|}
\hline No & $\mathbf{X}_{\mathbf{i}}$ & $\overline{\mathbf{x}}$ & $\mathbf{X}_{\mathbf{i}}-\overline{\mathbf{X}}$ & $\left(\mathbf{X}_{\mathrm{i}}-\overline{\mathbf{X}}\right)^{2}$ & $\mathbf{S}$ & Error & $\mathbf{N}^{\prime}$ \\
\hline 1 & 658.21 & \multirow{10}{*}{657.807} & 0.403 & 0.162409 & \multirow{10}{*}{0.3881} & \multirow{10}{*}{0.2776} & \multirow{10}{*}{7.508} \\
\hline 2 & 657.82 & & 0.013 & 0.000169 & & & \\
\hline 3 & 658.51 & & 0.703 & 0.494209 & & & \\
\hline 4 & 657.13 & & $\begin{array}{l}- \\
0.677\end{array}$ & 0.458329 & & & \\
\hline 5 & 657.62 & & $\begin{array}{l}- \\
0.187\end{array}$ & 0.034969 & & & \\
\hline 6 & 656.60 & & $\begin{array}{l}- \\
1.207\end{array}$ & 1.456849 & & & \\
\hline 7 & 658.28 & & 0.473 & 0.223729 & & & \\
\hline 8 & 657.50 & & $\begin{array}{l}- \\
0.307\end{array}$ & 0.094249 & & & \\
\hline 9 & 658.56 & & 0.753 & 0.567009 & & & \\
\hline 10 & 657.84 & & 0.033 & 0.001089 & & & \\
\hline Sum & 6578.07 & & & 3.49301 & & & \\
\hline
\end{tabular}

The calculation of the amount of replication

Description $: t_{n-1}, \frac{\pi}{2}=2.262, \mathrm{~S}=0,3881, \mathrm{n}=10$

$\mathrm{e} \quad=\frac{\left(t_{n-1} \cdot \frac{\alpha}{a}\right) \mathrm{s}}{\sqrt{n}}$ 


$$
\begin{aligned}
& =\frac{(2.262) \times 0.3881}{\sqrt{10}}=0.2776 \\
\mathrm{~N}^{\prime} & =\left[\frac{\left(z_{\alpha / 2}\right) \mathrm{s}}{\bullet}\right]^{2} \\
\mathrm{~N}^{\prime} & =\left[\frac{(1.96) \times 0.3881}{0.2776}\right]^{2}=7.508 \approx 8
\end{aligned}
$$

Thus, replication is needed is 8 , so that the data has been simulated been sufficient because for $N>N{ }^{\prime}=$ $10>8$.

\subsection{Verification Test}

Model verification test conducted at the time the model is run, these facilities are not brought information that the model is problematic or it can be said that the model runs smoothly as desired, so that the simulation model is in compliance verification test models.

\subsection{Validation Test}

Validation test is done to see if the simulation models are created has represented a real system that exists. Test validation using Paired-Samples T Test.

By using the following hypotheses:

- $\quad \mu 1=$ output real system

- $\quad \mu 2=$ output simulation system

- $\mathrm{H} 0: \mu 1=\mu 2$ : Average real system output is equal to the average output of the simulation system

- $\quad \mathrm{H} 0: \mu 1 \neq \mu 2$ : Average real system output is not equal to the average output of the system

- $\quad$ Simulation

4.4. Manual Calculations

Here is a table of manual calculations to find TCount is as follows:

Table 4.2 Calculation $T_{\text {count }}$

\begin{tabular}{|l|l|l|l|l|l|l|l|}
\hline Replication & $\begin{array}{l}\text { Output Real } \\
\text { System (Actual) }\end{array}$ & $\begin{array}{l}\text { Output } \\
\text { System } \\
\text { Simulation }\end{array}$ & $\mathbf{d}$ & $\bar{d}$ & $\mathbf{d}^{2}$ & $\mathbf{d}-\bar{d}$ & $\mathbf{d}^{\mathbf{d}-\bar{d})^{2}}$ \\
\hline 1 & 532.51 & 658.21 & -125.70 & 11.42 & 15799.51 & -137.11 & 18800.45 \\
\hline 2 & 648.97 & 657.82 & -8.85 & 11.42 & 78.32 & -20.27 & 410.81 \\
\hline 3 & 658.43 & 658.51 & -0.08 & 11.42 & 0.007044 & -11.50 & 132.31 \\
\hline 4 & 607.66 & 657.13 & -49.47 & 11.42 & 2446.98 & -60.89 & 3707.055 \\
\hline 5 & 620.60 & 657.62 & -37.02 & 11.42 & 1370.28 & -48.44 & 2346.046 \\
\hline 6 & 630.56 & 656.6 & -26.04 & 11.42 & 678.28 & -37.46 & 1403.44 \\
\hline 7 & 730.09 & 658.28 & 71.81 & 11.42 & 5156.89 & 60.39 & 3647.30 \\
\hline 8 & 828.13 & 657.5 & 170.63 & 11.42 & 29115.88 & 159.22 & 25349.45 \\
\hline 9 & 681.82 & 658.56 & 23.26 & 11.42 & 540.88 & 11.84 & 140.14 \\
\hline 10 & 753.48 & 657.84 & 95.64 & 11.42 & 9147.45 & 84.22 & 7093.62 \\
\hline Total & 6692.26 & 6578.07 & 114.19 & 114.19 & 64334.48 & 0.00 & 63030.62 \\
\hline Average & 669.23 & 657.81 & 11.42 & & & & \\
\hline $\begin{array}{l}\text { Standard } \\
\text { Deviation }\end{array}$ & 79.42 & 0.59 & 79.39 & & & & \\
\hline Variance & 6308.06 & 0.35 & 6303.06 & & & & \\
\hline
\end{tabular}

Standard Deviation $=\sqrt{\frac{\sum(d i-\Phi)^{2}}{N-1}}$

$$
\begin{aligned}
& =\sqrt{\frac{(532,51-669,23)^{2}+\cdots+(758,48-669,23)^{2}}{10-1}} \\
= & 79,42 \\
\text { Variance } \quad=\sigma^{2} & =\frac{\sum(d i-d)^{2}}{N-1} \\
& =\frac{(532,51-669,28)^{2}+\cdots+(758,48-669,23)^{2}}{10-1}
\end{aligned}
$$




$$
=6308,06
$$

Description :

$$
\begin{array}{ll}
\mathrm{n} & =10 \\
\mathrm{~d}_{0} & =0
\end{array}
$$

- $\mathrm{sd}$

$$
\begin{aligned}
-\operatorname{sd} & =\sqrt{\frac{n \sum_{i=1}^{1 n} d i^{2}-\left(\sum_{i=1}^{12} d i\right)^{2}}{n[(n-1)}} \\
& =\sqrt{\frac{10(64334,48)-(114,19)^{2}}{10(10-1)}} \\
& =83,68 \\
& =\frac{d-d 0}{8 d \sqrt{n}} \\
& =\frac{11,42-0}{83,68 / \sqrt{10}} \\
& =0,43
\end{aligned}
$$

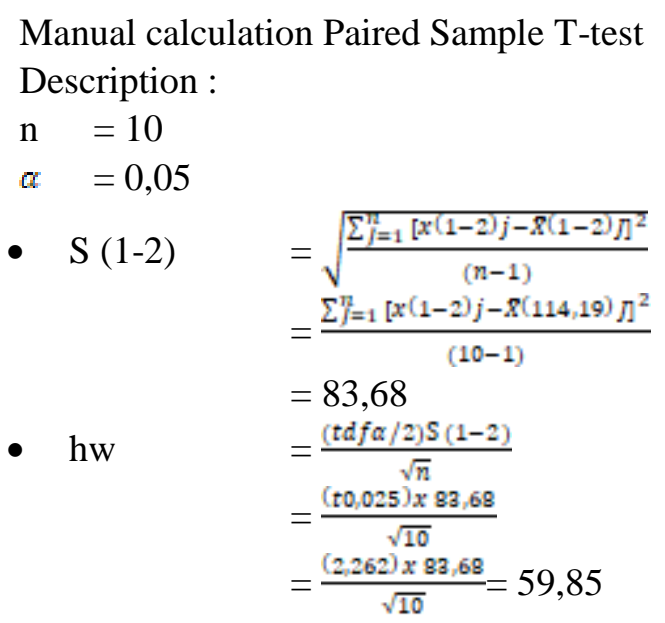

$(\bar{X}(1-2) \quad-\mathrm{hw} \leq \mu 1-\mu 2 \leq(\bar{X}(1-2)+\mathrm{hw}(11,42) \quad-59,85 \leq \mu 1-\mu 2 \leq \quad(11,42)+59,85-$ $48,43 \leq \mu 1-\mu 2 \leq 71,27$

Based on the results of manual calculations paired sample t-test passes with the interval $-48.43 \leq \mu 1-$ $\mu 2 \leq 71,27$ dan based on the results of statistical calculations with the $\mathrm{T}_{\text {count }}$ test using a software amounted to 0.431 so $\mathrm{T}_{\text {count }}<\mathrm{T}_{\text {table }}(0.431<2.26216)$. If visits by significance (2-tailed) of 0.676 has a value greater than (0.05) $\mathrm{H} 0$ is accepted and H1ditolak then there is no statistical difference between the real system output and output simulation system (Averiil, 2006).

After validation of the model are met, then performed the design of the proposed improvements consisting of three alternatives are as follows:

1. The model proposed fixes 1 , the addition of resources in the form of a forklift to move the finished coil from the engine to the storage appender which aims to optimize the production process of packaging a coil. The addition of a forklift is done for $\%$ idle (\% unemployed) in packaging and\% waiting (\% wait) in appender percentage is high, so that when the forklift working from the station of packaging through to storage operator at station of packaging idle and when the forklift working of the appender machine to the station packaging the machine is waiting (delay). Therefore, in order to avoid the bottleneck then needed the addition of a forklift. 


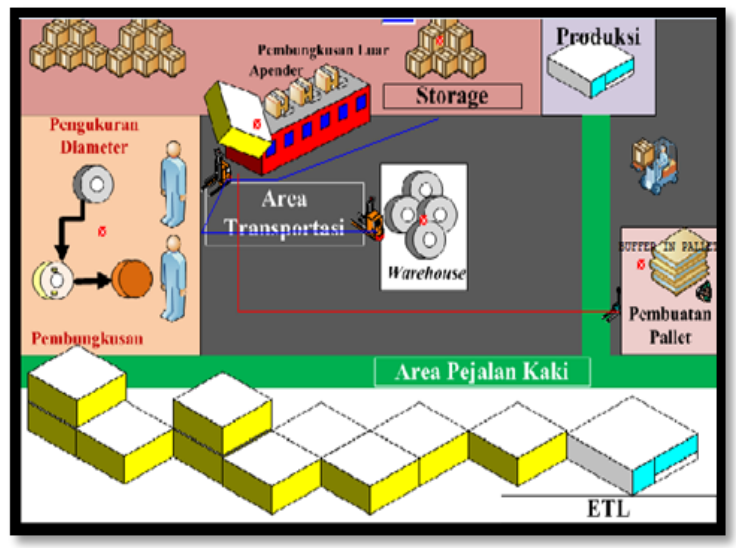

Figure 4.2 Model Proposed Improvements 1 Coil Packaging PT. Plates Timah Nusantara

2. Improvements proposed model 2 is the separation of work element on the appender machine that is the station of mounting crown. Where previously the appender machine used for the installation of pallet and install crown. It aims to optimize the time of production process of packaging coilagar is not the bottleneck on the appender machine.

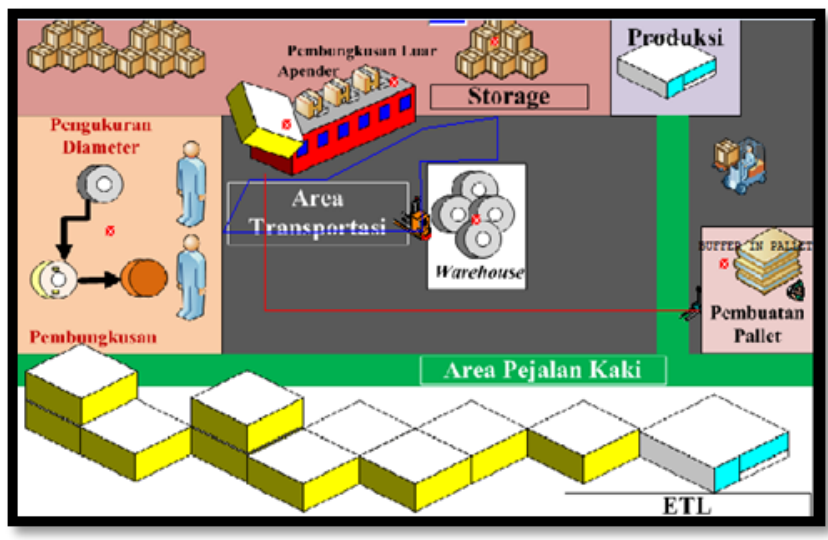

Figure 4.3 Model Proposed Improvements 2 Coil Packaging PT. Plates Timah Nusantara

3. Improvements proposed model 3 is an amalgamation of Proposed Improvements 1 and 2 in which the addition of resources in the form of a forklift to move the finished coil from the appender engine to storage and installation of additional stations crown.

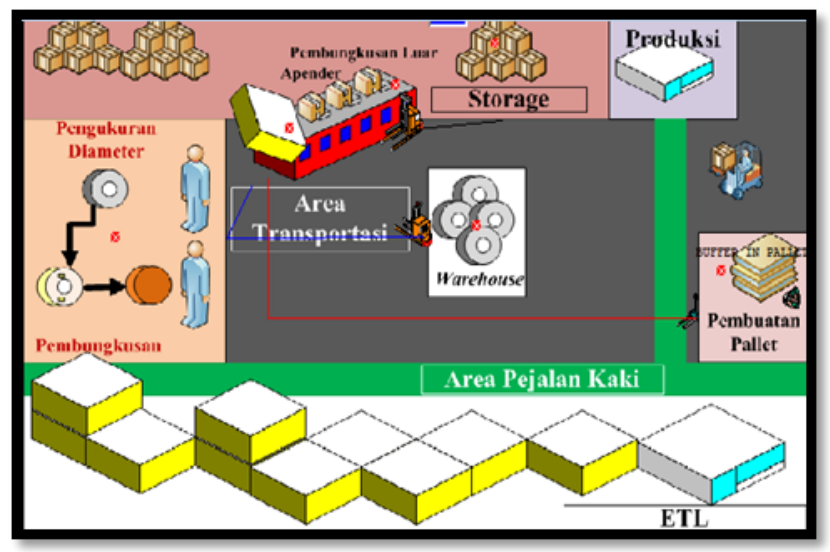

Figure 4.4 Model Proposed Improvements 3 Coil Packaging PT. Plates Timah Nusantara

After the proposed improvements to be made, then do the comparison of the simulation to see if there is a time difference of coil packaging process on Existing simulation systems, the proposed improvements 1 , the proposed improvements 2, and the proposed improvements 3. Comparison of simulation results using ANOVA following: 


\begin{tabular}{|c|c|c|c|c|}
\hline Replication & $\begin{array}{l}\text { Exsisting } \\
\text { System } \\
\text { (Hours) } \\
\end{array}$ & $\begin{array}{c}\text { Proposed } \\
\text { Improvements } \\
1 \text { (Hours) }\end{array}$ & $\begin{array}{c}\text { Proposed } \\
\text { Improvements } \\
2 \text { (Hours) }\end{array}$ & $\begin{array}{c}\text { Proposed } \\
\text { Improvements } \\
\mathbf{3} \text { (Hours) }\end{array}$ \\
\hline Replikasi 1 & 658.21 & 482.61 & 458.65 & 314.10 \\
\hline Replikasi 2 & 657.82 & 486.05 & 462.69 & 314.85 \\
\hline Replikasi 3 & 658.51 & 483.00 & 463.05 & 314.34 \\
\hline Replikasi 4 & 657.13 & 486.50 & 462.33 & 318.06 \\
\hline Replikasi 5 & 657.62 & 482.75 & 459.02 & 314.92 \\
\hline Replikasi 6 & 656.60 & 486.06 & 463.20 & 314.81 \\
\hline Replikasi 7 & 658.28 & 486.73 & 464.40 & 314.50 \\
\hline Replikasi 8 & 657.50 & 486.99 & 462.30 & 318.60 \\
\hline Replikasi 9 & 658.56 & 486.05 & 462.09 & 314.20 \\
\hline $\begin{array}{c}\text { Replikasi } \\
10 \\
\end{array}$ & 657.84 & 482.94 & 457.99 & 314.58 \\
\hline Average & 657.807 & 484.968 & 461.572 & 315.296 \\
\hline St. Dev & 0.622987 & 1.872003 & 2.194355 & 1.62701 \\
\hline
\end{tabular}

By using the following hypotheses:

- Ho $=\mu 1=\mu 2=\mu 3=\mu 4$

Thus, there are no significant differences between the existing models, the proposed improvements 1 , the proposed improvements 2 and 3 proposed improvements.

- $\mathrm{H} 1=\mu 1 \neq \mu 2 \neq \mu 3 \neq \mu 4$

Thus, there are significant differences between the existing models, the proposed improvements 1 , the proposed improvements 2 and proposed improvements 3 .

- With real level selected was $95 \%$, so $\alpha=5 \%=0.05$

Here are the results of ANOVA calculations manually:

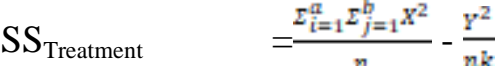

$$
\begin{aligned}
& =\frac{43271005+23519396+21304871+9941157}{10}-\frac{19196.43^{2}}{10(4)} \\
& =591069.772 \\
& \mathrm{SS}_{\text {Total }} \\
& =\frac{E_{i=1}^{m} E_{j=1}^{b} \Sigma_{i k=1}^{c} Y^{i} i k^{2}}{n}-\frac{Y^{2}}{n k} \\
& =\frac{658.21^{2}+657.92^{2}+658.51^{2}+\cdots+314.58^{2}}{-} \\
& =\frac{19196.43^{2}}{10(4)} \\
& =591171.966 \\
& \mathrm{SS}_{\text {Error }} \quad=\mathrm{SS}_{\text {Total }}-\mathrm{SS}_{\text {Treatment }} \\
& =591171.966-591069.772 \\
& =102.194 \\
& \mathrm{~S}=10, \mathrm{k}=4 \\
& \text { DoF SS } \text { Treatment }=\mathrm{k}-1 \\
& =4-1=3 \\
& \text { DoFSS }_{\text {Error }} \quad=\mathrm{k}(\mathrm{n}-1) \\
& =4(10-1)=36 \\
& \text { DoF } \mathrm{SS}_{\text {Total }}=\mathrm{df}-\mathrm{SS}_{\text {Treatment }}+\mathrm{df}-\mathrm{SS}_{\text {Error }} \\
& =3+36 \\
& =39
\end{aligned}
$$

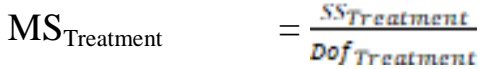

$$
\begin{aligned}
& =\frac{591069.772}{a}=197023.257 \\
& \mathrm{MS}_{\text {Error }}=\frac{3 S_{\text {Rrrer }}}{\text { Dof }_{\text {Rrrar }}} \\
& =\frac{102.194}{36}=2.839
\end{aligned}
$$

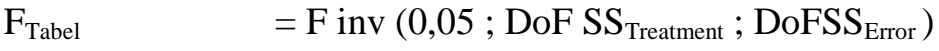

$$
\begin{aligned}
& =\mathrm{F} \text { inv }(0,05 ; 3 ; 36) \\
& =2.866 \\
& \mathrm{~F}_{\text {Hitung }}=\frac{\text { MS }_{\text {Tramatnent }}}{\text { MS }_{\text {Rrwar }}}
\end{aligned}
$$




$$
\begin{aligned}
& =\frac{19702 \mathrm{a} .257}{2.939} \\
& =69405.770
\end{aligned}
$$

Based on calculations manually and ANOVA using SPSS software that has been likened, the value Fhitung 69405.770 and Ftable value of 2,866. Thus the value $F_{\text {count }}>F_{\text {table }}$ is 69405.770> 2866, then kesimpulanya is reject Ho or accept $\mathrm{H}_{1}$ (Averill, 2006). This means that at least one difference from existing conditions, the proposed improvements 1 , the proposed improvements 2 and 3 . You can also see the proposed improvements the significance value / sig (P-value) is $0.000<0.05$ then it shows that the differences were considered significant.

In the above ANOVA test results is not known what is different and what difference is there, then it needs to be done with LSD (Least Significant Difference). LSD in the following calculations:

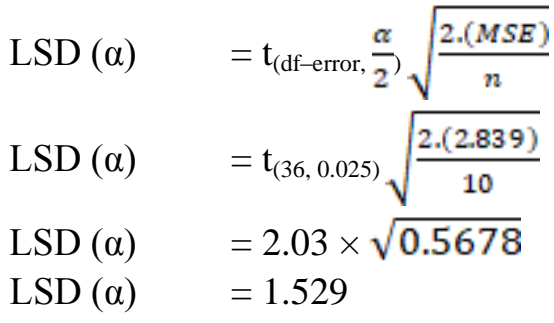

\begin{tabular}{|c|c|c|c|}
\hline Status & $\begin{array}{l}\text { Proposed } \\
\text { Improvements } 1 \\
\left(\bar{X}_{\Sigma}=484.968\right) \\
\end{array}$ & $\begin{array}{l}\text { Proposed } \\
\text { Improvements } 2 \\
\left(\bar{X}_{\bar{x}}=\mathbf{4 6 1 . 5 7 2}\right) \\
\end{array}$ & $\begin{array}{l}\text { Proposed } \\
\text { Improvements } 3 \\
\left(\bar{x}_{4}=315.296\right) \\
\end{array}$ \\
\hline $\begin{array}{l}\text { Proposed Improvements } \\
\text { Eksisting } \\
\left(\bar{X}_{1}=657.807\right)\end{array}$ & $\begin{array}{l}\left|\bar{X}_{1}-\bar{X}_{2}\right|=174.819 \\
\text { Signifikan } \\
172.839>1.529\end{array}$ & $\begin{array}{l}\left|\overline{X_{1}}-\overline{X_{2}}\right|=235.828 \\
\text { Signifikan } \\
196.235>1.529\end{array}$ & $\begin{array}{l}\left|\bar{X}_{1}-\bar{x}_{4}\right|=343.248 \\
\text { Signifikan } \\
342.511>1.529\end{array}$ \\
\hline $\begin{array}{l}\text { Proposed Improvements } 1 \\
\left(\bar{x}_{\bar{I}}=484.968\right)\end{array}$ & & $\begin{array}{l}\left|\bar{X}_{2}-\bar{X}_{2}\right|=61.009 \\
\text { Signifikan } \\
23.396>1.529\end{array}$ & $\begin{array}{l}\left|\bar{X}_{2}-\bar{X}_{4}\right|=168.429 \\
\text { Signifikan } \\
169.672>1.529\end{array}$ \\
\hline $\begin{array}{l}\text { Proposed Improvements } 2 \\
\left(\bar{x}_{\bar{s}}=461.572\right)\end{array}$ & & & $\begin{array}{l}\left|\overline{K_{Q}}-\bar{X}_{4}\right|=107.42 \\
\text { Signifikan } \\
146.276>1.529\end{array}$ \\
\hline
\end{tabular}

Table 4.4 Results of Calculation Least Significant Difference (Lsd) Manual

Based on Table 4.4 the calculations above it can be concluded that all three proposals of the proposed improvements improvements 3 has the highest mean difference in the amount of 342511 . The result of his decision is a simulation model that is best for coil packaging proposed improvements $3>$ proposed improvements $2>$ proposed improvement $1>$ existing proposals. Then the repair proposal selected was proposed improvement 3.

\section{Conclusions And Recommendations}

Conclusions and suggestions obtained based on the data processing is done.

\subsection{Conclusions}

Here is the conclusion obtained from the study:

1. The simulation model existing in the process of product packaging tin plate type coil is composed of Locations namely warehousing, packaging, buffers in pallet, pallet manufacture, Apender and storage, and 4 Entity is coil, pallet, beam and finished coil. Arrivals the arrival of a coil product from warehouse to the packaging station and the arrival of a buffer beam in pallet to pallet manufacture. And two resources, namely forklift pallet and forklift coil.

2. Proposed improvements are selected based on the results of simulation to optimize the processing time is 3 models proposed improvements with the addition of resources in the form of a forklift to move the finished coil from the engine appender to storage and installation of additional stations crown.

3. When the optimal coil packaging process is 315296 hours / month.

\subsection{Suggestion}

As for suggestions that are needed in this study are as follows: 
1. Researchers should be more careful in modeling problems exist in coil packaging systems.

2. The company should make improvements to the coil packaging process in accordance with the best improvement proposal.

3. The company should establish worker-hour shift in accordance with the simulation model

\section{REFERENCES}

Averill Law. Simulation Modeling and Analysis with Expertfit Software. McGRaw-Hill, New York. 2006

Charles R. Harrel, Biman K. Gosh, dan Royce O. Bowden. Simulation Using Promodel. McGRaw-Hill, New York. 2003.

Daellenbach, Hans G. System and Decision Making : A Management Science Approach. Chichester: John Wiley \& Sons, Ltd. 1994. 